\title{
Conversation Analysis as a Discourse Approach to Teaching Speaking Skill
}

\author{
Dinar Dipta \\ University of Darussalam Gontor \\ e-mail:dinardipta@unida.gontor.ac.id
}

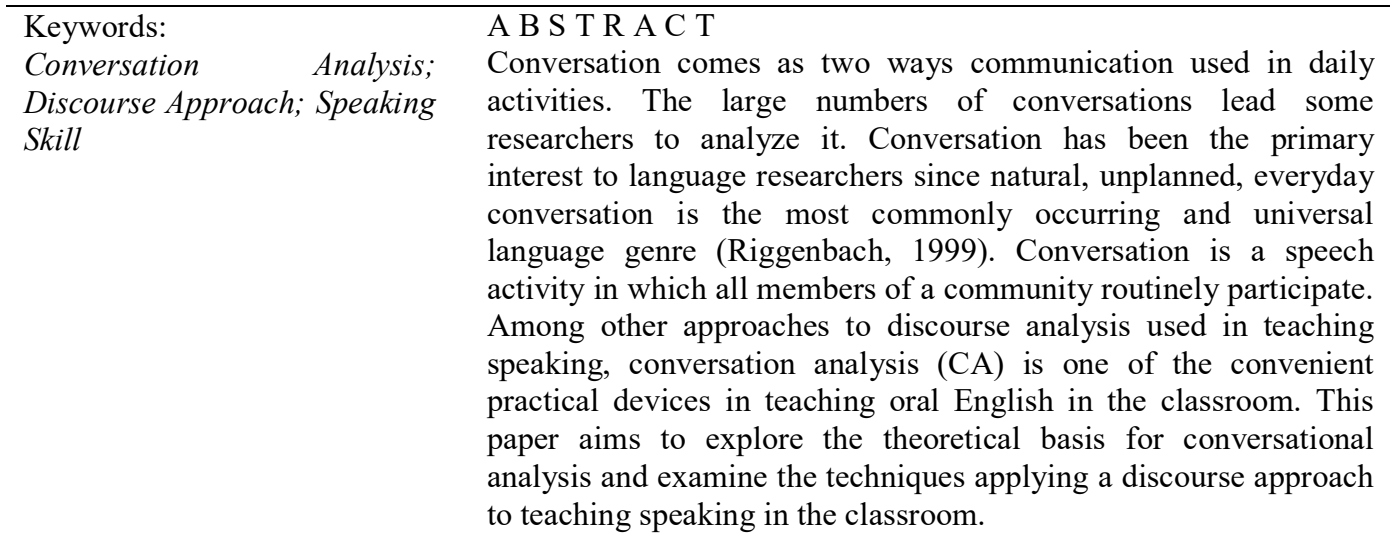

\section{INTRODUCTION}

The main goal of learning language is primarily to communicate with others. The participants in communication involve speakers and hearers. Therefore, this kind of communication leads to two ways communication. It means that people cannot speak without the consideration of the hearers. This two ways communication often called as conversation. Conversation is a speech activity in which all members of a community routinely participate. Based on Riggenbach (1999), conversation has been the primary interest to language researchers since natural, unplanned, everyday conversation is the most commonly occurring and universal language genre. Moreover, conversation happens in social life and it takes place in a certain situation; such as in office or classroom, market, coffee shop, restaurant and inside a certain culture. Therefore, the oral communication cannot be separated with the social and cultural context.

Considering the fact that oral communication cannot be separated with the social and cultural context, automatically the teaching of speaking should be taught regarding to the social and cultural context. To cope with it, the role of discourse analysis comes in the first place. In contrast to traditional way of teaching speaking, discourse analysis provides a new perspective on teaching and learning speaking skill. Discourse analysis refers to the study of the relationship between language and context (Kristina, 2013). It focuses on the skills needed to put the knowledge into action and to achieve successful communication (Cook, 1989). Discourse analysis has some approaches to use in teaching English skills. Each of approaches is designed to give a new point of view in order to develop the way of teaching English skills; as a mean that the teaching is not only done by giving the theory or the basic knowledge but also concerning on how to use it in the social context.

In relation to the importance of teaching oral English skill based on the social and cultural context, this paper takes one perspective of discourse approaches, conversation analysis (CA), 
attempting to explore the ways or techniques of applying CA to teaching speaking in the classroom and the benefits of fostering speaking skills using this discourse approach.

\section{METHOD}

This research was conducted using discourse analysis concerning in conversation analysis.It refers to the study of the relationship between language and context (Kristina, 2013). It focuses on the skills needed to put the knowledge into action and to achieve successful communication (Cook, 1989). The researcher attempting to explore the ways or techniques of applying CA to teaching speaking in the classroom and the benefits of fostering speaking skills using this discourse approach. This paper examines the sample of conversational analysis using the authentic material recorded from CNN news (an interview program), namely Larry King Live at CNN. The interview was uploaded on February 27th, 2007 by ProgressiveAmericaTimes.Com in youtube. The video of interview was downloaded from https://www.youtube.com/watch?v=7i8oBO-dpEY.

\section{RESULTS AND DISCUSSION}

Speaking as one of productive skills tends to be the most important skill in English. Being able in using English to communicate with others means that the students have achieved the goal of learning speaking. To succeed in speaking, students have to be taught with appropriate materials supported by certain techniques related to teaching speaking. Since language is a habit and should be learned everyday therefore, the teaching of speaking should give not only the theoretical issue on the use of speaking but also practice and apply the language directly related to the social situations. This idea brings an ideal condition of teaching speaking which should cover all the micro and macro skills of speaking. Mastering these skills lead the students to use language well.

Regarding to micro and macro skills of speaking, these skills are used as the basic requirement to create some media and techniques in teaching speaking. Brown (2004) stated micro skills require the students to be able to produce: differences among English phonemes and allophonic variants, chunks of language of different lengths, stressed and unstressed words, reduced forms of words and phrases, fluent speech at different rates of delivery, grammatical word patterns, speech in natural constituents, a particular meaning in different grammatical forms, and cohesive devices in spoken discourse. While the macro skills show that the students should be able to: appropriately accomplish communicative functions according to situations, use appropriate styles and other sociolinguistic features in face-toface conversations, convey links and connections between events and communicate such relations as focal and peripheral ideas, convey body language and other nonverbal cues along with verbal language, and develop a battery of speaking strategies such as emphasising key words and accurately assessing how well the hearer is understanding their speech by looking at their expression whether it is nodding their head, etc.

After understanding the features of micro and macro skills, it can be concluded that indeed the micro skills can be taught using traditional teaching of speaking for example lecturing section or theoretical learning. On the other hands, the macro skills require the students to learn the language with its context. Here the students are asked to use and apply their 
knowledge in the real social life. That is why to achieve the goal of teaching English skills should be done using discourse approaches. Especially for teaching speaking, one of the perspectives of discourse approaches namely conversation analysis will give some benefits by applying this in the classroom.

c. Conversation Analysis

Conversation analysis is one of the practical devices in teaching oral English in the classroom. It explores the patterns of social life represented in a conversation or dialogue (Kristina, 2013). The analysis of conversation was first put forward by Sacks, Schegloff and Jefferson in 1974 (as cited in Kristina, 2013), initially focusing on studying the smallest units of conversation and it is important in the study of conversational norms, turn-taking, and other aspects of spoken interaction. Moreover, Kristina (2013) proposed that the discourse analysts primarily take a point of view of conversation analysis influenced by ethnomethodological tradition.

Richards et al. (1992) suggest that conversation analysis refers to the analysis of natural conversation in order to discover what the linguistic characteristics of conversation are and how conversation is used in ordinary life. In this case, conversation is not restricted to casual and informal talk, but it also includes all forms of talk in interactions (Schegloff et al., 2002), such as talks in educational environment, in workplace or in classroom. It concerns about the macro-level features of discourse including power, value systems, prestige and status, and the micro-level features of discourse including falling or rising intonation, stressed or unstressed syllabus, and grammatical structures (Riggenbach, 1999).

To be specific, major concepts of conversational analysis, at least, should cover turn taking, adjacency pairs, and repair (Sacks et al. as cited in McCarthy, 1991). The first concept is turn taking. Turn taking deals with when and how speakers take turns in spoken conversation. Burns, et al. (1996) mentioned some signals or different features of conversation marks, for example; (1) overlaps mark instances of disagreement, urgency, and annoyance, or a high degree of competition for a turn; (2) little competition for turns marks interactions which are more cooperatively negotiated; and (3) pauses between turns may indicate that a speaker is searching for the correct response or is signaling that an unanticipated response is likely. The second concept of conversation analysis is adjacency pair. Adjacency pair is a sequence of two related utterances by two different speakers; the second utterance is always a response to the first (Richards et al., 1992). Burns et al. (1996) suggest adjacency pairs as the patterns which occur in conversation when the utterance of one speaker is likely to be followed by a particular kind of response and the response can be either a preferred response or a dispreferred one.

The third concept in conversational analysis is repair. It is a term for ways in which errors, unintended terms, or misunderstandings are corrected by speakers or others during conversation (Richards, et al. 1992). There are four types of repair according to Hutchby and Wooffitt (1998) consisting of self-initiated self-repair, other-initiated self-repair, selfinitiated other-repair, and other-initiated other-repair. The sample of conversation analysis is explained in the following section.

d. The Importance of Using Authentic Materials in Conversation Analysis

Conversation analysis of discourse highlights the importance of using authentic materials. Riggenbach (1999) stated that authenticity of text is crucial for insight into actual language 
use. Somehow created own example leads to a bias and intentionally carry a meaning. Rather than created examples of sentences and structures by thoughtful methods, most language researchers interested in discourse using real data such as someone talk, audiotaped, videotaped, or written data.

Using authentic materials is required based on two reasons. Firstly, scripted materials differ in some aspects from authentic materials. Fragmented utterances, meaning negotiation, backchannels, overlaps, hesitations, lexical choices which are often frequent in real-life communication are rare to see in scripted materials (Burns et al., 1996). However, indeed, scripted texts may be helpful to the students at a certain stages of learning (Burns et al., 1996). Unfortunately in EFL classroom, the students are always asked to scripted texts. As a result, they are hardly able to apply it in the real language situation. Secondly, by involving the students in analyzing authentic oral discourse, they are no longer role as the receiver of the knowledge but the researchers (Riggenbach, 1999). Thus, they are more willing to take part in the activities targeted the real-life communication.

The following information examines the sample of conversational analysis using the authentic material recorded from CNN news.

1) Information about where, when, how the text was collected

This part of conversation is an extract from an interview program, namely Larry King Live at CNN. The interview was uploaded on February 27th, 2007 by ProgressiveAmericaTimes.Com in youtube. The video of interview was downloaded from https://www.youtube.com/watch?v=7i8oBO-dpEY.

2) Relevant social and cultural information

Larry King Live is one of the popular talk shows in the world. King has presented many shows over the decades and has interviewed presidents, prime ministers and many other famous celebrities. The extract is collected in his interview with the wife of ex president of United States George W. Bush, Laura Bush. Laura Bush made an appearance on Larry King Live where she complained about the media showing "The one bombing a day that discourages everybody".

3) Transcription of the text

The following parts of conversations are the transcription of Larry King (as the host) and Laura Bush (as the guess) interview in Larry King Live at CNN.

(1) King: Has the war, eh.. what is the good term.. wearied you down? I mean the public obviously is.. more people disapprove than approve. It is hard to standing in presidency. How was.. hh.. how was it done to you?

(2) Bush: Well, of course it is wearying. A wearying. There is no doubt about it and I understand how the American people feel and that, they um.. feel like things aren't going like we wanted them to there. On the other hand, I know how important it is for us to continue to help the Iraq is, and actually now would be serious mistake, and I really agree with the president on that. That we.. um.. The Iraq government is gave up and running, um.. as fast as they can and of course we want our tribes to come home. Nobody wants war. No one pros war. We want them, um.. to be able to have a.. a democracy there to have the people in Iraq who have been crashed by dictatorship for all this year to able to build a good government that represents everyone, and I think it will happen. Is it gonna be fast? No, and we never expected it to be fast.

(3) King: So, it is gonna be gone on when you leave office? 
(4) Bush: Probably. I mean, I have no idea. There is no way I can predict but I hope not. I hope that they can um.. build their government and um.. reconcile with each other and build their country. This is their opportunity to seize the moment.. um.. to build a really good and stable country. And many parts of Iraq are stable at now, but of course, what we see on television is that one bombing a day that discourages everybody.

(at the end of the interview)

(5) King: Well, last time we met was at the conventions, great spending this time.

(6) Bush: Thank you so much. It is an honor for me, I really appreciate it.

(7) King: You're welcome. Laura Bush.

4) Conversation analysis

a. Turn taking

In this conversation, King, the interviewer has a structure for questions and knows where the conversation should flow. He initiates questions one after another and turns are well managed with a few overlaps marking urgency. Besides, little competition for turns indicates interactions which are cooperatively negotiated. In the view of the nature of the interview, the turn size of interviewee is much bigger than that of the interviewer. Details of the turntaking are composed as follows:

\section{Line Turn Taking}

1 King gives the turn to Bush by raising a question.

2 Bush takes the long turn by answering the question.

3 King claims the turn, for he is eager to further his question; and Bush keeps her floor, which constitute an overlap.

4 Bush takes the turn.

$5 \quad$ King takes the turn by closing the interview.

6 Bush takes the turn by thanking to King as the host.

$7 \quad$ King takes the turn by answering to Bush statement and close the program.

b. Adjacency pair

It is found a series of question and answer adjacency pair from the interview. In an interview, the interviewer always dominates the direction of the conversation and asking questions. Therefore the interviewee role is answering those questions. In this interview, all the questions are followed by preferred responses. Detail analysis of the adjacency pairs is listed as follows:

\section{Adjacency pair First pair Second pair part}

1 Line 1 Question Line 2 Answer

2 Line 3 Question and confirmation request Line 4 Answer and confirmation

3 Line 5 Compliment Line 6 Answering compliment and thanking

4 Line 7 Answering thanking and greeting

c. Repair

In this conversation, both King and Bush have self initiated self-repairs. In line 1, King selfrepaired his question by correcting his term. Bush, in line 2 and 4 makes her self-repairs for her unintended forms in her answers by saying the words I mean followed by her correction. 
e. Conversation Analysis in Teaching Speaking

Choosing the classroom activities are not easy decisions. It is known that conversation analysis activities are built on the use of the authentic materials get from social interaction. In Riggenbach's (1999) model, learners are involved in discourse activities both as researchers and learners. Teachers play as a co-researcher and facilitator. Despite this, applying this model in teaching practice should consider in some factors that may constrain the development of the discourse activity. The first factor to consider is the access to the authentic data on how the learners can get the authentic data. Riggenbach (1999) suggested that people who have ever lived abroad can serve as the subjects if there is a lack of authentic data but it is also not an easy way to do. Second factor to take into account is the students' mastery level. However, the way of ongoing scaffolding in teaching may be a good way to solve these two problems.

Burns and Joyce (1997) suggested that the criterion for choosing particular activities is to see if they can help students develop knowledge and skills in using spoken language. It is important that the students need to understand the aim of activities before participating in it. It will raise learners' awareness of the learning process and give them an idea of where the lesson is going. The following is a series of sequenced activities designed to senior high school students with a view to developing speaking skill related to ordering food in a restaurant situation based on the concept of five categories of scaffolding by Burns and Joyce (1997).

Level Intermediate

Skill Speaking Skill

Context Ordering for food

Time Allotment 100 minutes

Aims Raising students language awareness and skill (micro skill)

Raising students discourse awareness and skill (macro skill)

Source Conversation of people ordering delivery food

Video of people ordering food in a restaurant

Transcript of the conversation:

Waiter: Hello, Lee's Garden Cuisine. What would you like to order?

Man : Hello, can I have your specials?

Waiter: Sure, Sir. We have wonton noodles, hakka noodles, crispy lamb, um.., vegetables, chicken or pork dim sums.

Man : Okay. I like to order um...wait what is it.. wonton noodles and chicken dim sum for two.

Waiter: Is that all, Sir? Would you like to order starters or um, maybe soup?

Man : Umm.. no thanks, that's it. My address is 42 Beverly Street.

Waiter: Okay, your order will be delivered within 30 minutes. Will you be paying in cash?

Man : Yep, okay no problem.

Waiter: Please pay the delivery boy $\$ 34$.

Man : Yeah, alright.

Waiter: Thank you. Hope to serve you again soon.

Procedures

1) Preparation activities 
The aim of preparation activities is to put learners into the context of the target interaction situations and make them understand which type of spoken interaction they will produce (Burns and Joyce, 1997). In this case, the students deal with restaurant situation in which they need to be quite familiar with the process of ordering foods and beverages. The following activities may be used in this situation:

- Brainstorming: (10 minutes)

The teacher asks the students the following questions and makes their lists. The questions are:

1. Have you ever ordered delivery food?

2. What do you know about ordering delivery food or beverages?

3. What kinds of questions do you need to ask before you order the foods?

2) Language awareness and skills acquisition activities

To facilitate the students to participate in the coming spoken interaction, teachers are expected to design some activities concerning vocabulary and sentence structures (Burns and Joyce, 1997). The following activities may be used:

- Pair work: information gap (10 minutes)

Student A is going to ask student B the definition of the word in his own card. Sample cards are as follows:

Student A: Word

Beverage

Meal

restaurant, etc.

Waiter

restaurant

Waitress

Order

Menu

Cashier

Bill

Appetizer

Main course

\section{Student B: Definition}

a list of the food that you can eat in a restaurant

a person whose job is to receive and pay out money in a shop, bank, a woman whose job is to bring the food to customers at their tables in a sweet food eaten at the end of a meal a small amount of food eaten before a meal a drink of any type the food which is eaten on such an occasion a meal eaten in the late morning; a combination of breakfast and lunch a meal that is eaten in the middle of the day

the main meal of the day, usually the meal you eat in the evening but sometimes, in Britain, the meal eaten in the middle of the day

Dessert the largest or most important part of a meal in which there are different parts served separately

Lunch a request for payment of money owed, or the piece of paper on which it is written

Dinner restaurant

Brunch restaurant or shop

- Sentence builds: pair work (5 minutes)

Students are expected to work in pairs to rearrange the word groups into a sentence. Student A first gives Student B a word group, student B builds a sentence based on the word group. Then they change the roles. Sample word groups are as follows: 
$\begin{array}{llll}\text { Group 1: order } & \text { menu } & \text { bill } & \\ \text { Group 2: waiter } & \text { appetizer } & \text { beverage } & \text { brunch } \\ \text { Group 3: waitress } & \text { lunch } & \text { main course } & \\ \text { Group 4: dinner } & \text { dessert } & \text { meal } & \text { cashier }\end{array}$

3) Discourse awareness and skills acquisition activities

Transcribing is a good practice to prepare students for oral communication. Students should be able to own their texts therefore they have a personal affective involvement in the certain context. The activity is designed as follows:

- Transcribing recorded conversation (30 minutes)

Procedures:

Divide the students in groups consists of 4 members.

Give the direction of transcribing and hand out tapes and cassette recorder of ordering delivery foods.

Guide the learners to transcribe (based on related words and sentences worked out)

Ask a group representative to report and display their transcript on slides.

Hand out the semi-scripted conversation version and raise students' awareness to compare it with their scripted version.

- Group discussion (10 minutes)

Procedures:

Ask the students to tell how people order delivery foods.

Guide the students to do conversation analysis to see how adjacency pairs, turntaking and repair are organized.

Ask students to work in groups to practice question-answer adjacency pairs using different context.

4) Interaction activities

At this stage, students are to practice and act out how to apply language related to ordering food in a restaurant. The activities are designed as follows:

- Role-play (20 minutes)

Procedures:

Students work in groups to prepare acting from the script (change the telephone conversation into a real face-to-face conversation).

Rehearsal period.

Presentations.

5) Extension activities

This part of activities usually help students reinforce what they produced and make them more confident with their performance. The activities could be:

- Video observation (15 minutes)

Previously the teacher has videotaped students' role-plays in interaction activities. This time the teacher shows some clips in the classroom and gives comments in class. Teachers then present the class a clip of video on the topic of ordering food in a restaurant to familiarize students with more real situations and discuss it.

\section{CONCLUSION}


Based on the theoretical analysis above, it can be concluded that conversation analysis can be used as the convenient practical devices in teaching oral English skill which cover both micro and macro skills of speaking. Furthermore, those findings can be implemented in teaching speaking for intermediate learners. To be applied in teaching upper intermediate and advance learners, the topic and authentic media can be varied regarding to the principles of conversational analysis.

\section{REFERENCES}

Brown, H. D. (2004). Principles and Classroom Practices. New York: Longman.

Burns, A., Joyce, H., \& Gollin, S. (1996). I See What You Mean: Using Spoken Discourse in the Classroom. Sydney: National Centre for English Language Teaching and Research, Macquarie University.

Burns, A., \& Joyce, H. (1997). Focus on Speaking. Sydney: National Centre for English Language Teaching and Research, Macquaire University.

Cook, G. (1989). Discourse. Oxford: Oxford University Press.

Hutchby, I. \& Wooffitt, R. (1998). Conversation Analysis: Principles, Practice and Applications. Cambridge: Polity Press.

Kristina, D. (2014). Discourse Analysis and Language Teaching. Surakarta: Universitas Sebelas Maret.

Larry King Live at CNN. (2007). Retrevied from: https://www.youtube.com/watch?v=7i8oBO-dpEY.

McCarthy, M. (1991). Discourse Analysis for Language Teachers. Cambridge: Cambridge University Press.

Richard, J., Platt, J., \& Platt, H. (1992). Longman Dictionary of Language Teaching and Applied Linguistics. London: Longman.

Riggenbach, H. (1999). Discourse Analysis in the Language Classroom: Volume 1 The Spoken Language. Ann Arbor: University of Michigan Press.

Schegloff, E. A., Koshik, I., Jacoby, S., \& Olsher, D. (2002). Conversation Analysis and Applied Linguistics. Annual Review of Applied Linguistics, 22, 3-31. Retrieved from: http://dx.doi.org/10.1017/S0267190502000016 